\title{
MOȘTENIREA METAFIZICĂ (EZOTERICĂ) SORESCIANĂ
}

\section{N.N.Negulescu}

$\mathrm{Cu}$ câteva excepții, criticii timpului l-au definit pe poetul, dramaturgul, prozatorul, eseistul şi traducătorul Marin Sorescu (n. 29 febr. 1936, Bulzești, Dolj-d. 8 dec. 1996, București) ca "fiind", citez: "un spirit epigramistic, cinic-interogativ, descendent din manierismul poantelor, parodist, lirist fantast, avangardist (literar,n.a.), demitizator (prin reinterpretare, n.a.) a marilor mituri ale umanității șamd (vezi Petru Poantă, p. 425-427, Dicționarul Scriitorilor Români, Ed. Științifică Și Enciclopedică, București, 1978). În încheierea prezentării exemplificată, criticul hunedorean Petru Poantă nota: "Dacă nu a modificat poezia, el a distrus, în orice caz, o prejudecată: aceea referitoare la purism și metafizic.“ Evaziv. Continuarea acestui material va oferi orientări lămuritoare.

\section{PUNTEA DINTRE UNIVERSURI}

În aprilie, 1997, Fundația Scrisul Românesc din Craiova, a lansat prin Ed. Creuzet, ediția anastatică a ultimei culegeri de poezii "PUNTEA" (111 p.), sub semnătura poetului Marin Sorescu. Ilustraţia coperteor şi grafica interioară sunt preluate din abundenta producție plastică a autorului. Pagina de gardă a cărții prezintă o tulburătoare notă asupra ediției:’Ediția de față însumează ultimile poezii ale autorului. Ele au fost scrise pe filele uneimai vechi agende, de format $11 \times 15$ centimetri, cu o copertă din material plastic, de culoare roșie.

Majoritatea poeziilor au fost dictate din acest caiet soției, autorul operând corecturi şi stilizări în timpul dictării. Alte poezii au fost dictate direct, fără să existe $o$ variantă olografă; sunt poezii, dintre cele nedatate, pe care autorul nu a avut puterea să le scrie (Editura)". Dedicaţia poetului, împărtășită "Tuturor celor care suferă", este de fapt o cheie testamentară a profunzimii creației, în sfera căreia se zbuciumă tumultul revărsărilor spirituale.

Înainte de a emite judecăți axiologice asupra volumului, care a încheiat ansamblurile artei sale universale, într-o ipostază absolută de sacrificiu, prin onticitatea încărcăturii de sensuri din structura dramatis- mului expresiv, guvernată de justețea accentului, dar şi prin amploarea tensiunii emoționale ce se degaja torențial din athlon-ul Sinelui cu presimțitul Înger al Morții, trebuie să mărturisesc că, m-am străduit să descifrez $\mathrm{cu}$ onestitate transfigurările artistice ale autorului aflat pe atunci în adevărata lui natură. Lecturând conținutul genuin al elegiilor, vom observa cum, în fiecare din noi, Marin este reflectat de ochii cuvinelor...

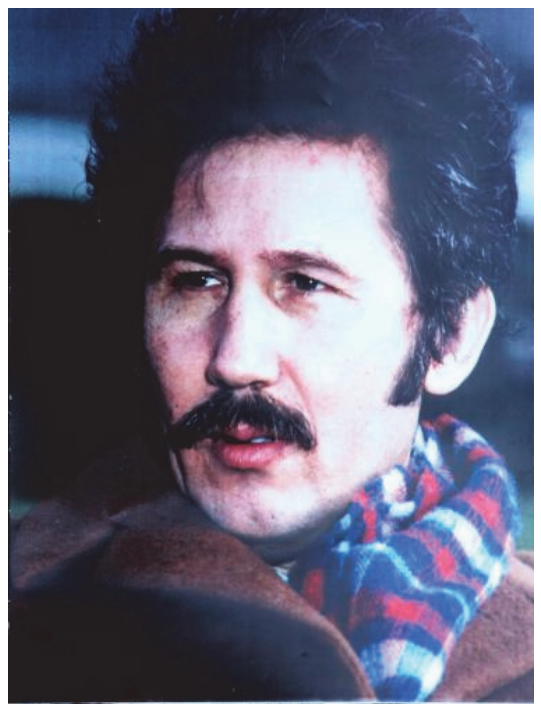

Privită unitar, scriitura poetică a operei, transmisă prin filtrul rațiunii, vădește intense emanaţii telurice şi cosmogonice care, amenință spațiul lăuntric, invadând ființa. 
Ideea (eidos) fondatoare a elegiei “Cineva" e stăpânită de angoasa însingurării şi, deschide poarta de intrare în inima universului creator. Sunt aici figurate prin antiteză patru nivele ale ființării: invocaţia eikon-ului solar "Vino la căpătâiul bolnavului, soare, / Mîngâie-i obrazul /Cu raza ta de rădăcină a vieții /"; revolta ascendentă ("giulgiul"), unde tonul poetic ia gradat forma interjectivă "Cerule, bântuit de atâta energie cosmică / De la mii de sori și stele, /Energie atât de miraculoasă, /Ți-am cerut o fărâmă, / Te-am implorat în genunchi, / Dacă nu mi-ai dat / Păstreaz-o pentru tine / Și să ți-o bagi în ochi.“; chemarea thymos-ului "Strângeți-vă în jurul meu, prieteni, / Vino, Doamne, și Tu și plânge-mi de milă. / O să-mi facă bine hohotul vostru, / Aduce a viață./“; și tautocronia spiritului eclipsat de teama misterioasă "Cineva taie cu foarfece / Drumurile mele, / Le peticește în batjocură / Și le aruncă la câini. /"'(1.XI.1996).

Dacă în prima elegie, firea poetului simte nevoia prezențelor sensibile și suprasensibile consolatoare, purtându-și povara suferinței la diferite dimensiuni, în cea de a doua creaţie "Singurătate", sentimentul solitudinii se intensifică. Astfel încât, celula fonică a monologului interogativ este stilizată în plan imagistic-gestual, fiind preluată alternativ de dinamica dintre suferind și o secvență dorită; rol însușit de "căpătâiul" personificat și înzestrat cu virtutea înțelepciunii liniștitoare: "La căpătâiul bolnavului / Doar căpătâiul - / Și-a ridicat capul de pe el / Și, de parcă, acum 1-ar vedea / Îl întreabă: / - Ai venit și tu să stai cu mine, / Căpătâiule ? / - Da ! / Trebuie să fie cineva lângă tine / În ceasurile astea, / Fiindcă ești tare bolnav. /'(2.XI.1996).

Înțeleasă metafizic, simbolistica proiecțiilor temporale din primele două versuri "La căpătâiul bolnavului / Doar căpătâiul /"ne dezvăluie întru adevăr, capătul de drum al finitudinii, deodată, fiind în act cu aura veghetoare; ceea ce mai generează în înţeles filosofic și duala apropiere predestinată a des/ființării. Deși pornește de la forțele senzoriale, rezultate din Lumea sa etherică, "Puntea"imaginară, ca reper liminar cu acute armonii semantice, progresează rectiliniu dintr-un punct aprins, spre transcendența escatologică. Semnificațiile existente, emit iradiații care ne induc în magia durerii lingvistice: "Mă balansez pe ceva foarte şubred / Un fel de punte primejdioasă, / Străbătută de spasmele / Unui teribil vârtej; / O punte între nimic și nimic / Pe care eu n-am cerut s-o trec. /“"

Cum observăm, "balansul” între ni/mic și ni/mic (ca instabilitate de echilibru a eului, între finitudine și infinitudine) "pe ceva foarte şubred“, nu este lipsit de primejdia căderii, în viziune biblică. Balansul (vibrația pendulatorie) ne relevă drumul ispitei ce proliferează în contact cu singurătatea și izolarea laică, o spaimă a ființei spre / de neființare, într-o finalitate adâncă, bine călăuzită în text de "coincidența" contrariilor "între nimic și nimic." Dar "nimicul ", redat aici exoteric, nu este totuna cu predicția haosului sau a abisului, trăită esoteric în subtilitatea soresciană.

Chiar dacă pentru mulți pare o utopie, el, poetul nivelurilor superioare, știe că noțiunile exoterice de haos și abis, neînțelese de lumea profană, sunt ascunderi hermetice, în spatele cărora se află o "uzină"misterioasă, genezică, universală, unde se petrec metamorfoze elementale (nu elementare !): "Niciodată nam făcut / Atâtea gesturi dezordonate,/ Semănând a rugă, amenințare, disperare.../ Sunt azvârlit în cer / Printre tunete / Revin, / Iar mă azvârle / Niciodată n-am fost atât de speriat.“

Îmi probez temeinicia afirmaţiei cu un fragment revelator, extras din "Sfânta predică", rostită de Hermes Trismegistus: "3. [...] Căci în Haos era un întuneric nesfârşit. Abis sau Adâncime fără fund, Apă și un Spirit inteligibil în putere; și a țâşnit Lumina Sfântă, 
iar elementele s-au coagulat din Nisipul substanței umede. 4. Şi toți Zeii au văzut Natura plină de semințe.

Studiind temeinic Cosmogonia, Max Heindel emitea următoarea teză: "Haosul nu este o stare care a existat în trecut și care acum a dispărut în întregime. El ne înconjoară chiar în acest moment. Vechile forme avându-şi pierdută utilitatea, se dizolvă, unele după altele, în Haosul care dă naștere în mod constant în schimb la noi forme. Fără acest dublu proces nu ar putea să existe progres; munca evoluției ar înceta și stagnarea care ar urma ar împiedeca orice posibilitate de înaintare. Este un adevăr de netăgăduit că “cu cât murim mai des, cu atât trăim mai mult. "Iar Goethe, poet iniţiat, a scris: "Cel care nu poate în mod constant să moară și să renască la viaţă va fi mereu un oaspete trist pe acest pământ. "Și Sf. Pavel s-a exprimat convingător: "Eu mor în fiecare zi. “

Pe alte imagini ale întinderii spațiale, răsună o poruncă fermă, sosită prin hățișul de determinări: “- Dă-te jos de pe linia asta / închipuită, / Nu înțelegi că totul s-a terminat ? / Sunt azvârlit, trântit, dat cu capul / de pereți/ Mă sprijin, mă agăț / Mă ridic. / - N-am știut că viața / E o linie închipuită, zic./ Zmuciturile mă fac jucărie / Pe scândura șubredă, între pământ și cer.“ Iată cum, la apusul târziului, ratio își asumă ultima participație la reinițiere prin accedere pe as/cuţitul perasuluiliniar. "Linia închipuită" rămâne aparent deasupra substanței poetice, care precede sensul; un concept voit de uniformitate, un simbol oponent al spiralei din teoria atracției universale, o alt/fel de cale aleasă a microcosmosului uman înspre pluralitățile Lumilor macrocosmice.

Potenţialitatea symtomieidevastatoare din conștiința poetică pare a se diminua, cel puțin fulgurant, în amestec cu identicul inocenței ce transpare prin rememorarea copilăriei: "Ce departe a rămas în urmă leagănul / Din acelaşi lemn ca şi puntea / În care mama, cîntând şi plîngând, / Mă învăța ritmul cosmic / Pe care1 pierd acum: / Nani ! Nani ! / “(2.XI.1996).

Prin alternarea timpilor în registrul litaniei, Ființa din Cuvânt, investește acum raynnoismulnucleului creativ cu empyrikosul nuanțelor soteriologice, fiindcă retrăiește esențele ritmurilor siderale.

Asocierea componentelor alegorice, exprimate gnomic de personalitatea sensibilă care valorizează, se desășoară în perspectiva umană, dar este interconectată și la procesele galactice dintre universuri.

Impulsionat de curenții vitali, Marin Sorescu preferă Sciencia Occulta în această enigmatică și inedită construcție vizionară. Într-un alt episod dramatic, sufletul hiperconștient, care nu mai suportă impuritățile concretului, aspiră la realităţile invizibile. Primatul voinței sale era eliberarea din experiența existențială șireântoarcerea la aperionul originilor: "Oprește ! / A răcnit sufletul, / Oprește să mă dau jos ! / Sunt sătul de-atâtea corvezi, / De-atâtea determinări, obligații și legi, / Eu am fost făcut să fiu liber. / - Nu pot să mă opresc, / I-a răspuns pământul - Pământul dn mine -, / Dă-te jos din mers, / Dacă-ți dă mâna / Și fă-o chiar acum, / Când eu virez / Spre scârbă și tină. / Dă-te jos în cer, / Prietene de-o viață, / Te iau când revin,. /'(2.XI.1996).

Credința în succesiunile reântrupărilor, guvernate de mișcările astrelor, o regăsim în predicția vocativă "Te iau când revin. "

Perceptând ființial fluxul "Monadei divine" (Leibniz), poetul se "hipostaziază “, oficiind un ritual în cod psiurgic prin titlul de referință "Doamne!” (Spitalul Chochin, Paris, 10.XI.1996) şi renunță aparet la ecranul spațial, pe care s-a materializat imagistic, întro ordine vibratorie "puntea de lemn șubred ". Spun aparent, fiindcă, linia vieții eului în variațiile sale poetice se continuă... Intensa aspirație esoterică, protognostică, cheamă la cunoaștere superioară, atemporală și impersonală. 
Deci, din dorința de revenire în embrionul sufletelor, este implorat Numele Sacralității Creatoare: "Doamne, / Ia-mă de mână / Și hai să fugim în lume, / Să ieșim puțin la aer. / Poate schimbând curenții, / O să mă simt și eu în larg, / Lângă Tine. /" Dar, până la visata Lume Sublim-Emanaivă (Aziluth), ,fuga din Lumea factice (Asiah), va trebui să mai străbată în eternități cosmice Lumea formativă (Yetsirah), cât și Lumea creativă (Briah), potrivit Legii Virtuților Divine a Sephirothurilor Kabbalistice.

Spectrul matricei obiectualiste, văzut prin fereastra elegiei "Ficat locuit"(2.XI.1996) este configurat din energii prometeice: "Simt aripile vulturelui / Întinzând marginile ficatului meu; / Îi simt ghearele, / Îi simt pliscul de fier, / Setea lui de zbor. / Cine spunea că sunt înlănțuit ? /'Într-o astfel de formulă imperativă a genului, sesizăm fuziunea mytos-urilor (teogonic-elen: Teogonia lui Hesiod, (v. 521 - 522); zoroastrianist, indo-european și a celui cosmogonic, germanic-scandinav (Gotterdammerung) cu straturile înălțimilor ideatice; mytos-uri care, acumulează întreaga sarcină a tragismului canonic printr-o tainică alchimie hermetică.

Lexicul încrustat $\mathrm{cu}$ abstracțiuni nu suportă medierea cu "măștile morții": Am experimentat / În chinuri nemaipomenite / Vreo șapte-opt măştiale morții / Și toate mi sau părut îngrozitoare / "; dar modulează (prin călăuzirea conceptelor) psalmodierea penitenței: "Eu care am plâns în hohote / Pe ruina tuturor civilizațiilor / Pe mormane de tăblițe scrise / Și cărămizi zmălțuite, / De ce să nu plâng acum / Și pe ruina obrazului meu? /"(Măștile, 5.XI.1996). Odată cu explorarea stărilor limită, preluate din tiparul propriei existențe (și care a îndurat ciocniri atât de violente în tensiunile lor excesive) spiritului poetic îi transpare convingerea primară în unitatea indestructibilă a sufletului, îndreptățit să pornească în căutarea harismelor: "Un fir de păianjen / Atârnă de tavan, / Exact deasupra patului meu. / În fiecare zi observ / Cum se lasă tot mai jos. / Mi se trimite și / Scară la cer, zic. / Mi se aruncă de sus / Deși am slăbit îngrozitor de mult / Sunt doar fantoma celui ce am fost, / Mă gândesc că trupul meu / Este totuși prea greu / Pentru scara aceasta delicată. / Suflete, ia-o tu înainte, / Păș ! Păș ! /"(Scară la cer, 5.XI.1996).

Avându-și originea într-o voință liberă, gândurile revalorifică, scrutând cu luciditate antropologică deriva relativismului neputincios: "Observ cu interes / Cum luptă instinctul vieții / $\mathrm{Cu}$ geniul morții. / Viața vine cu o mie de tertipuri, / Moartea are o mie şi una de vicleșuguri. / Ca doi gladiatori, / Unul cu trident și plasă, / Altul cu spadă scurtă. / Sunt terenul de luptă. / Au rămas din mine / Doar ochii,/ Să vadă și să se îngrozească/" (Spectator, 6.XI.1996). Primele trei versuri "Observ cu interes / Cum se luptă instinctul vieții / $\mathrm{Cu}$ geniul morții / “, nu contestă Universalul, ci susțin prin El, dependenţa ontologică. Chiar dacă este "Strivit între logica misteroasă / A vieții / Și logica misterioasă a morții““, spiritul poetic nu tinde spre pervertire, ba dimpotrivă, el își conștientizează cu ochi văzători valoarea absolută a trecerii, rechemat la purificare și unificare cu principiile sacre: Alfa și Omega. Dar mysterium sacer conține esența adevărului și rămâne inaccesibil rațiunii omenești. De aici se propagă sentimentul "strivirii" în definirea formelor artistice pe care le analizăm. "Îngrozirea" poetică distinge "ipsum esse" (ființa prin esență) de "ființa prin participare" (Sf. Augustin).

În actul resemnării din "Durere pură" (6.XI.1996), realul și magicul versurilor cu aceleași contururi ascuțite, formează o nouă axă: "Nu mi-e rău ca să-mi fie bine, / Mi-e răuca să-mi fie rău [...]/" Paradigma se explică prin punerea în evidență a mashal-ului ebraic, ca formă literară a parabolei biblice. Fascicolul paroxistic al disperării energetice 
are un ecou, într-un fel de prezent etern, indeterminabil, ca un coșmar visat, stăpânit de oroare: "Fac scufundări în durerea pură, / Esență de coşmar și disperare, [...]/ "Interesant (ă) hairesis, aș zice, ales la răscruci de drumuri. Odysseia părăsește meandricul printr-o ilustrare logosferică: "Mă rog de împăratul peștilor / Să-mi trimită un rechin de treabă / Să-mi taie calea. /"Așadar, sufletul anthroposului celest, obține temperarea ultimei dorințe prin invocarea Simbolului Cristic Universal, care este "Împăratul peștilor“. Datorită acestei oglindiri "în substanța primordială, în hyle” (Platon) îl regsim pe poetul nostru și în creația dramaturgică "Iona ", călăuzit de același fir de aur. Un anumit grupaj elegiac din orizontul cărţii, va orienta probabil crezul criticii, către o părelnică tehnicizare eristică, care se degajă permanent în continuarea asemănării de motive. Însă, vorbirea destinului spiritual care clatină finitul și indefinitul în Solul Mării Albastre (9.XI.1996), Priveghi (1.XI.1996), Coșciug fricos (11.XI.1996), Bilanț (11.XI. 1996), Cartea Morții (19.XI.1996), Căderea în Sine (19.XI.1996), Prometeu bolnav (21.XI.1996) şi Berbecul cu coarne întoarse (nedatat), caută să îndestuleze setea pătimirii şi a morții credincioase. Este vârtejul final, țâşnit întru sfârșit de toate cele pământești; dar nesfârșit în eudaimonia angelică.

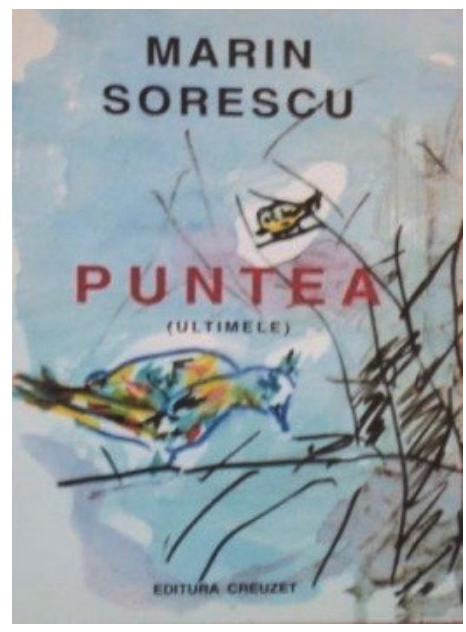

"Puntea" a întemeiat o scriere prin excelență oraculară, căreia îi vom înţelege travaliul artistic numai prinMarele Vis, însoțiți fiind de nostalgia depărtării. Ca și la Baudelaire, la sfârşitul procesului poetic, stă tonul de foc limpede "FEU CLAIR": "Mă întorc cu fața / la perete / Și le spun prietenilor / Îndurerați: / Mă întorc repede. "(nedatat).

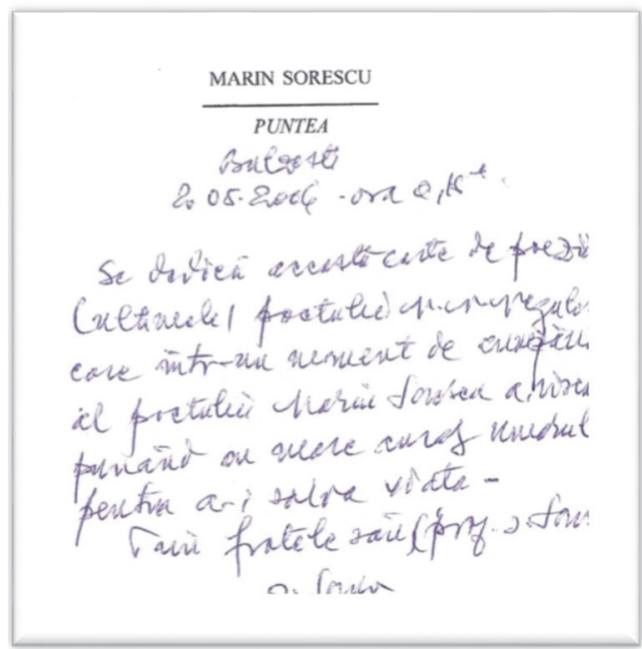

Textul dedicației lizibil: "Bulzești, 2.05.2006 ora 0,16 . Se dedică aceste poezii (ultimele) poetului N.N.Negulescu care într-un moment de cumpănă al poetului Marin Sorescu a riscat punând cu mare curaj umărul pentru a-i salva viața. Prin fratele său, prof. Ion Sorescu

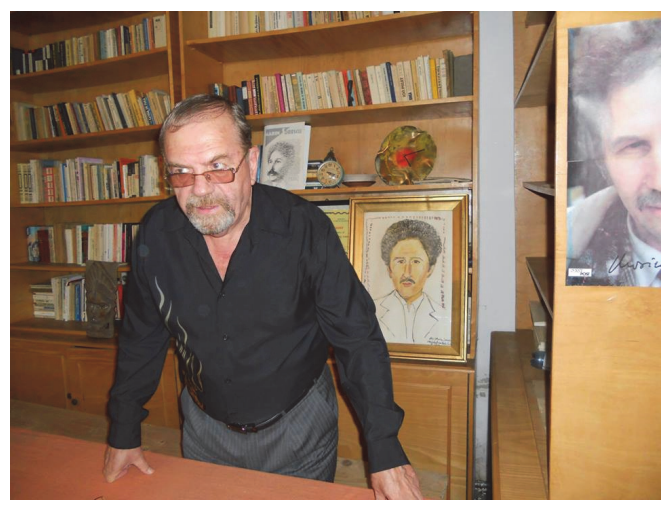

Poetul N.N.Negulescu, recitând un grupaj liric în Casa Memorială Marin Sorescu. 